\title{
Is it possible to predict who may never need treatment for B-CLL?
}

V. Galle, Ph. Vlummens, F. Offner

Department of Hematology, Ghent University Hospital, Belgium.

\section{AIM}

Prognostic factors of B-CLL overall survival have been extensively studied. There is, however, much less known about prognostic factors that can identify, at the time of diagnosis, patients who will never develop an indication for treatment.

\section{METHODS}

- We conducted a retrospective study of 156 unselected patients newly diagnosed with B-CLL at the University-Hospital-Ghent between 2000-2012.

- Demographics, lymphocyte count, RAI/Binet stage, lymphocyte doubling time, Catovsky-score, CD38, ZAP70, LDH, $\beta 2 M G$, IGHV-mutational status, cytogenetics and CLL-IPI were collected at diagnosis.

- We defined treatment free survival as the study endpoint.

- Analysis was performed using Kaplan-Meier estimate and significance was tested using the log-rank algorithm. Multivariate study was done by cox regression analysis. Reported $p$-values are 2 -sided with a significance level of $5 \%$.

\section{RESULTS}

- Median time-to-first-treatment was 4.7 years (0-16.6 years) (figure 1 ). Median follow-up was 7.7 years. Fifty-seven patients (37\%) did not need treatment.

- We saw, on univariant analysis, that elevation of $\beta 2 \mathrm{mg}$ and $\mathrm{LDH}$, an unmutated IGHV, del11q and del17p were able to identify patients needing treatment in more than $90 \%$ of cases (table 1, figure 2). It proved more difficult to identify patients not requiring treatment (table 2, figure 2).

- Multivariate analysis showed that normal $\beta 2 \mathrm{mg}$, low lymphocyte count, mutated IGHV and Binet $A$ have independent value, for prognosis prediction of who will not require treatment during follow-up (table 3, figure 3). Based on this data a prognostic index is currently under development.

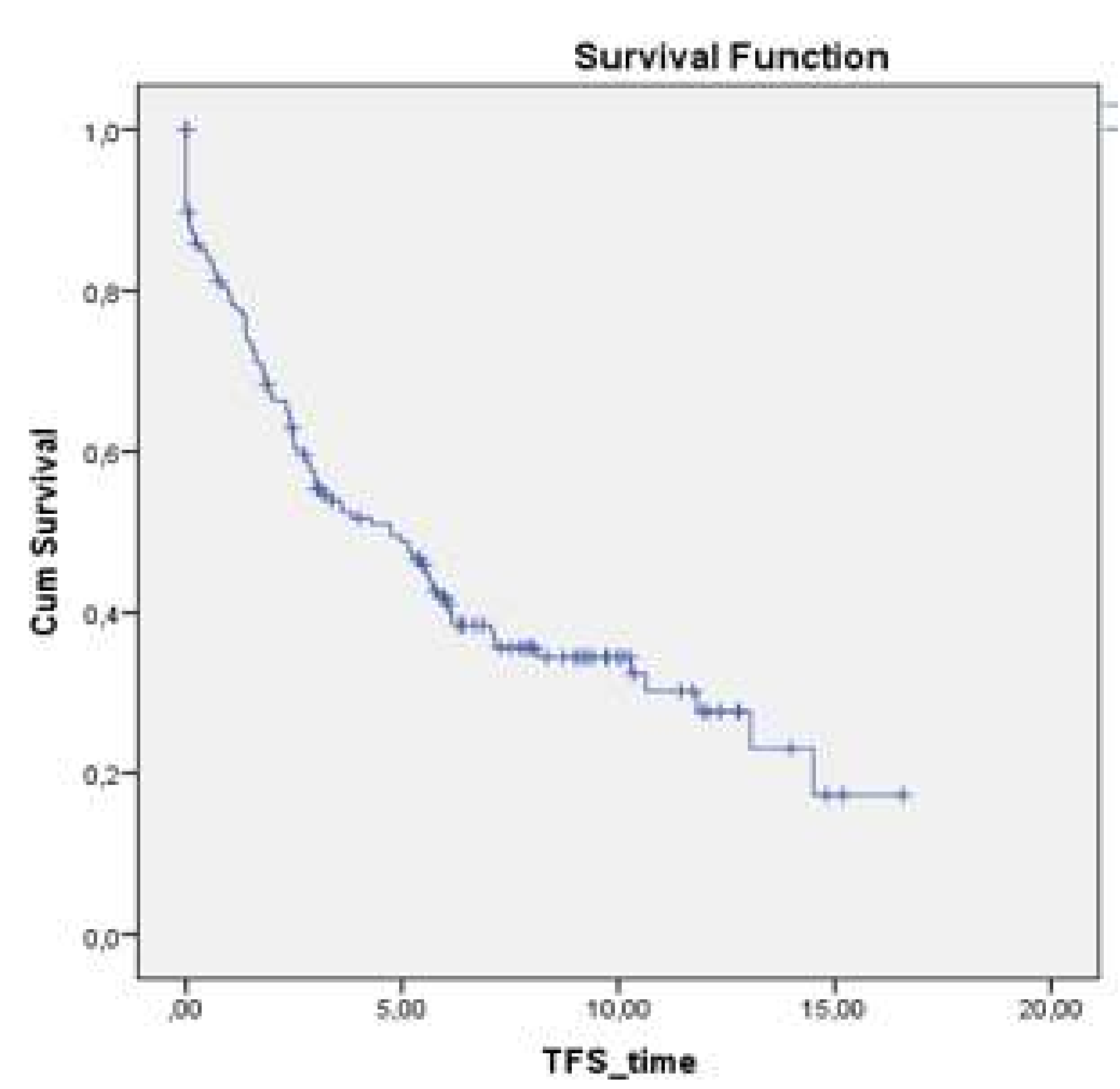

Figure 1: Treatment free survival (in years) of the entire population.
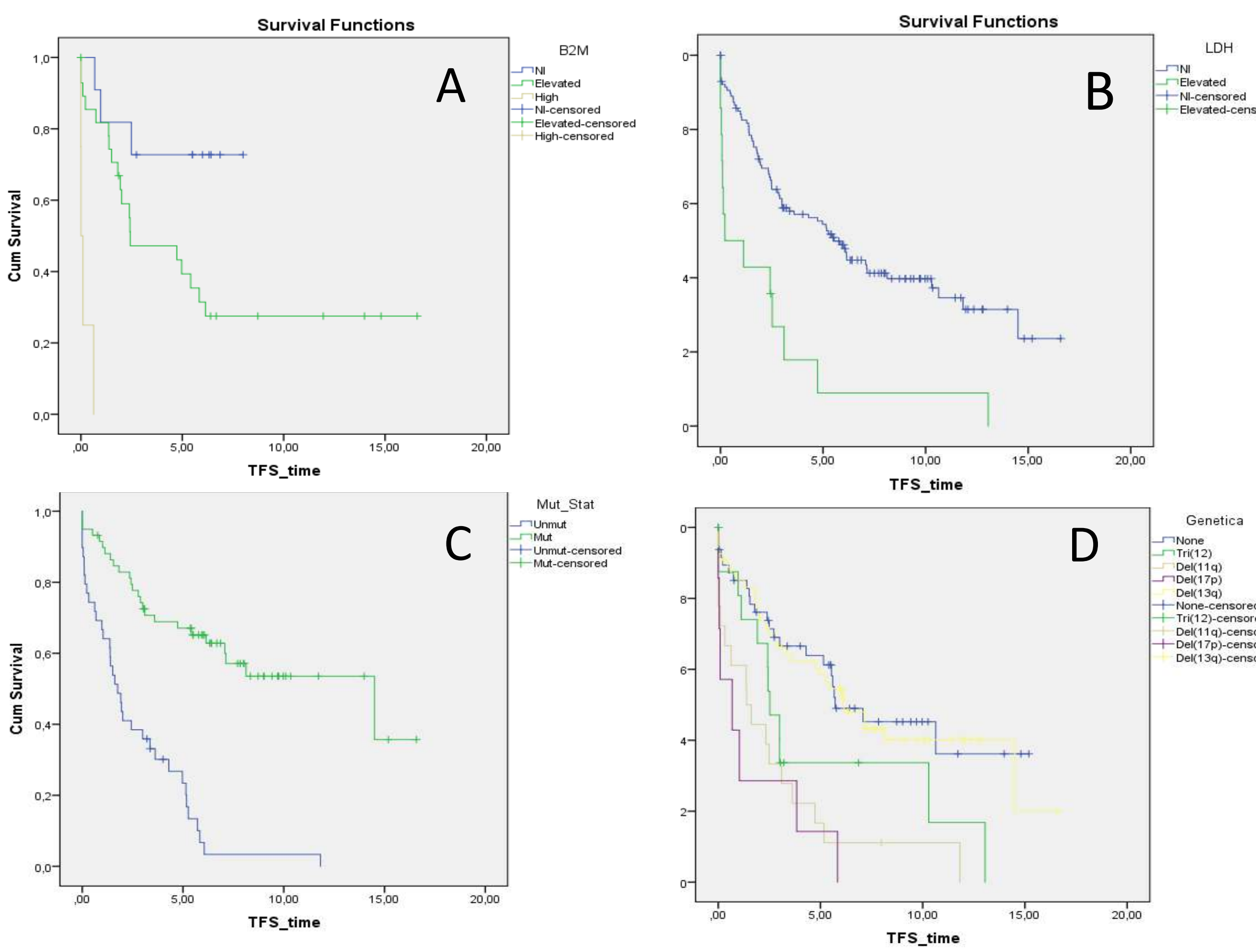

\begin{tabular}{|c|c|c|c|c|}
\hline \multicolumn{3}{|c|}{ Adverse risk factor PPV } & & \\
\hline Del17p & \multicolumn{2}{|c|}{$100 \%$} & \multicolumn{2}{|c|}{ Favorable risk factor NPV } \\
\hline$\beta 2 \mathrm{mg}>3,5 \mathrm{mg} / \mathrm{l}$ & \multicolumn{2}{|c|}{$100 \%$} & Normal $\beta 2 \mathrm{mg}$ & $73 \%$ \\
\hline ECOG 3 & \multicolumn{2}{|c|}{$100 \%$} & IGHV M & $58 \%$ \\
\hline IGHV U & \multicolumn{2}{|c|}{$95 \%$} & Del13q & $57 \%$ \\
\hline Del11q & \multicolumn{2}{|c|}{$94 \%$} & \multicolumn{2}{|c|}{ Normal cytogenetics 52\% } \\
\hline Elevated LDH & \multicolumn{2}{|c|}{$93 \%$} & Rai 0 & $48 \%$ \\
\hline \multirow{3}{*}{\multicolumn{3}{|c|}{$\begin{array}{l}\text { Table 1: Overview of the risk factors } \\
\text { with the highest predictive value of the } \\
\text { need for treatment during follow-up. }\end{array}$}} & ECOG 0 & $46 \%$ \\
\hline & & & Binet A & $45 \%$ \\
\hline & & & Normal LDH & $42 \%$ \\
\hline & & & \multirow{3}{*}{\multicolumn{2}{|c|}{$\begin{array}{l}\text { Table 2: Overview of the risk factors } \\
\text { with the highest predictive value for } \\
\text { the absence of need for treatment } \\
\text { during follow-up. }\end{array}$}} \\
\hline $\begin{array}{l}\text { Favorable risk } \\
\text { factor }\end{array}$ & HR & $\mathbf{p}$ & & \\
\hline Normal $\beta 2 \mathrm{mg}$ & 0,25 & 0,034 & & \\
\hline IGHV M & 0,31 & $<0,001$ & \multirow{3}{*}{\multicolumn{2}{|c|}{$\begin{array}{l}\text { Table } 3 \text { (left): Multivariate analyses } \\
\text { of the favorable risk factors. } \\
* \text { HR for each stepdown }(-10000 / \mathrm{mcl}) \text { in } \\
\text { lymphocyte count, starting from }>40\end{array}$}} \\
\hline Binet A & 0,38 & 0,003 & & \\
\hline \multicolumn{3}{|c|}{ Low lymphocyte } & & \\
\hline
\end{tabular}

Figure 2 (left): Treatment free survival (in years) stratified by $\beta 2 M G(A), L D H(B)$, IGHV (C) and genetics (D).

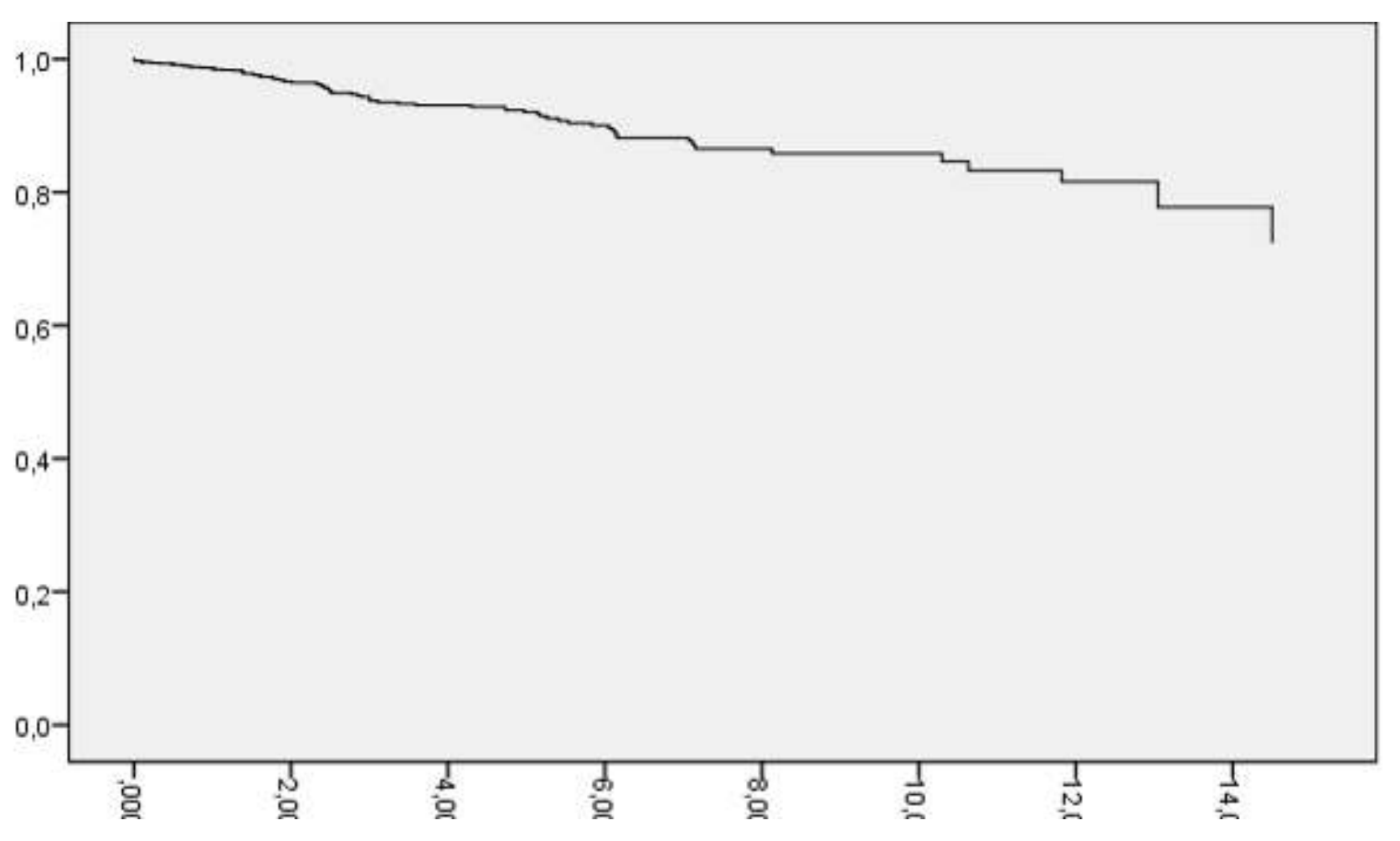

Figure 3: Treatment free survival (in years) prediction of the subpopulation with normal $\beta 2 \mathrm{MG}$, lymphocyte count < 10 000/mcl, mutated IGHV and Binet A.

\section{CONCLUSION}

In daily practice, it can be very useful to predict which patient with B-CLL will never need treatment. Based on the data presented, this is possible when we combine $\beta 2 M G$, lymphocyte count, IGHV status and BINET stage. A prognostic index that integrates this information is under development. Before implementation in daily practice, such an index needs validation true prospective, population-based, observational research; we hope to commence this study in the (near) future.

\section{REFERENCES}

- International CLL-IPI working group. An international prognostic index for patients with chronic lymphocytic leukaemia (CLL-IPI): a meta-analysis of individual patient data. Lancet Oncol. 2016;17(6):779-790.

- Wierda WG, O'Brien S, Wang X, et al. Prognostic nomogram and index for overall survival in previously untreated patients with chronic lymphocytic leukemia. Blood 2007; 109: 4679-85.

- Pflug N, Bahlo J, Shanafelt TD, et al. Development of a comprehensive prognostic index for patients with chronic lymphocytic leukemia. Blood 2014; 124: 4962. 